\title{
An easy way to estimate energy expenditure from hemodynamic data in septic patients $^{1}$
}

\section{Um modo simples de estimar o consumo de energia a partir de dados hemodinâmicos em pacientes sépticos}

\author{
Anibal Basile-Filho', Maria Auxiliadora Martinss ${ }^{\mathrm{II}}$, Flavio Marson ${ }^{\mathrm{III}}$, Paulo Roberto Barbosa Evora ${ }^{\mathrm{IV}}$ \\ I Associate Professor, Division of Intensive Care Unit, Department of Surgery and Anatomy, Ribeirão Preto Faculty of Medicine, \\ University of São Paulo, Brazil. \\ II MD, PhD and Surgeon-in-Chief, Division of Intensive Care Unit, Department of Surgery and Anatomy, Ribeirão Preto Faculty of \\ Medicine, University of São Paulo, Brasil. \\ III MD, PhD, Division of Intensive Care Unit, Department of Surgery and Anatomy, Ribeirão Preto Faculty of Medicine, University of São \\ Paulo, Brasil. \\ Iv Full Professor and Head, Division Thoracic and Cardiovascular Surgery, Department of Surgery and Anatomy, Ribeirão Preto Faculty of \\ Medicine, University of São Paulo, Brazil.
}

\begin{abstract}
Purpose: The purpose of this study is to compare the resting energy expenditure (REE) obtained by indirect calorimetry (IC) to the REE calculated by predictive equations (Brandi and Liggett) using the oxygen consumption $\left(\mathrm{VO}_{2}\right)$ obtained by Fick's method in septic patients. Methods: Prospective study in septic patients admitted in an intensive care unit of a university hospital. Fifteen adult patients (11 men and four women) were studied. $\mathrm{VO}_{2}$ measurements were made using a portable metabolic cart connected to a respirator and a pulmonary artery catheter. Results: The APACHE II at admission was $22.6 \pm 7.2$ with a mortality risk of $46.1 \pm 27.7 \%$. The mean REE obtained by IC and by the Brandi and Liggett equations were $1699 \pm 271,1815 \pm 355$ and $1361 \pm 277 \mathrm{kcal}$.day ${ }^{-1}$ respectively. There were no statistically significant differences between the two methods, with the two means showing a difference of 8.7\%. REE values were close for IC x BRANDI (r=0.80), but the IC x LIGGETT correlation was only 0.58. Conclusions: The results suggest that REE can be easily calculated by obtaining $\mathrm{VO}_{2}$ with the Swan-Ganz catheter and using the Brandi equation even for septic patients under mechanical ventilation.
\end{abstract}

Keywords: Oxygen Consumption. Resting Energy Expenditure. Indirect Calorimetry. Sepsis.

\section{RESUMO}

Objetivo: O objetivo desse estudo foi o de comparar o consumo de oxigênio em repouso (COR) obtido por calorimetria indireta $(\mathrm{CI})$ com valores do COR calculados por equações preditivas (Brandi e Ligget) que utilizam o consumo de oxigênio $\left(\mathrm{VO}_{2}\right)$ obtido pelo método de Fick em pacientes sépticos. Métodos. Estudo prospectivo em pacientes sépticos internados em unidade de terapia intensiva de um hospital universitário. Quinze pacientes adultos (onze homens e quatro mulheres). As medidas de $\mathrm{VO}_{2}$ foram realizadas usando um aparelho metabólico portátil conectado ao respirador e por cateter em artéria pulmonar. Resultados: O índice APACHE II na admissão foi 22.6 \pm 7.2 com risco de mortalidade de 46.1 $\pm 27.7 \%$. As médias do COR obtidas por CI e pelas equações de Brandi and Liggett foram, respectivamente, 1699 $\pm 271,1815 \pm 355$ e $1361 \pm 277$ kcal.day $^{-1}$ Não se observaram diferenças estatisticamente significantes entre os dois métodos com as duas médias mostrando uma diferenças de $8.7 \%$. Os valores de COR Também foram próximo dos valores de CI x BRANDI $(\mathrm{r}=0.80)$, mas a correlação com CI x LIGGETT apenas 0.58. Conclusões: Os resultados sugerem que o COR pode ser facilmente calculado para obter-se o $\mathrm{VO}_{2}$ com o cateter de Swan-Ganz e pelo uso da equação de Brandi para pacientes sépticos em ventilação mecânica.

Descritores: Consumo de Oxigênio. Consumo de Energia em Repouso. Calorimetria Indireta. Sepse.

1. Research performed at the Intensive Care Unit of the Ribeirão Preto Hospital of Clinics, Ribeirão Preto Faculty of Medicine, University of São Paulo, Brasil. 


\section{Introduction}

Acute disease and its treatment invariably alter the metabolism of critically ill patients, causing important changes in resting energy expenditure (REE). For this reason, an accurate determination of the REE of these patients is imperative, especially for patients in sepsis or septic shock. This insures their energy requirements, preventing the complications associated with hyper- or undernutrition whose deleterious consequences have been well documented. ${ }^{1,2}$ Many methods to assess the REE in critically ill patients have been described, but all of them have limitations. Indirect calorimetry, although being currently considered to be the "gold standard", has technical limitations such as requiring trained personnel with available time, the need for an inspired oxygen fraction of less than $60 \%$ and equipment of high cost. ${ }^{3,4}$ On the other hand, other existing methods involve predictive equations such as the classical equation of Harris \& Benedict. ${ }^{5}$, plus various stress factors, whose purpose is to predict the energy cost of metabolic changes in this patient population. ${ }^{6}$ These equations are extensively used because of their easy calculation and zero cost. However, these equations have proved to be imprecise in a wide variety of well-defined clinical situations, showing important inter- and intraindividual variations. ${ }^{7,8,9,10}$

Other methods developed some time ago and extensively used to calculate the REE are based on the Fick equation, which uses hemodynamic data such as cardiac output, serum hemoglobin concentrations, and mixed arterial and venous oxygen saturation obtained through a threelumen catheter inserted into the pulmonary artery. ${ }^{11,12,13}$

On the basis of information related above, the objective of the present study was to assess the REE of septic patients through the correlation between indirect calorimetry and two predictive equations obtained from hemodynamic data.

\section{Methods}

The present prospective clinical study was conducted in the Intensive Care Unit of the University Hospital of the Ribeirão Preto Medical School, University of São Paulo, Brazil. The project was approved by the Human Research Ethics Committee of the same Hospital and free informed consent was obtained in all cases. The study was conducted on 15 patients (11 males and four females) with septic shock after blood volume restoration and hemodynamic stabilization. The criteria used for the diagnosis of septic shock were those established by the consensus conference held by the American College of Chest Physicians/Society of Critical Care Medicine. ${ }^{14}$ Inclusion criteria were patients victims of septic shock from the third to the fifth day of evolution with an indication of invasive hemodynamic monitoring. Exclusion criteria were age $>85$ and $<15$ years, need for $\mathrm{FiO}_{2}$ (oxygen fraction in inspired air) $>60 \%$, mean arterial

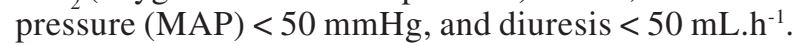

Upon admission to the Intensive Care Unit, all patients were stratified according to the APACHE II severity index ${ }^{15}$ and by the system of sepsis grading. ${ }^{16}$ Invasive and noninvasive hemodynamic monitoring, blood volume replacement, mechanical ventilation (Servo 900C, Siemens, Sweden), antibiotic treatment, administration of vasoactive drugs and nutritional therapy according to the REE calculated by indirect calorimetry were performed in all cases. The patients were sedated with benzodiazepines and/ or opiates and a neuromuscular blocker was used when necessary. Current patient weight was measured with a portable electronic scale (Slingscale 2002, Hill-Rom, Hillenbrand Industries, USA). The mean duration of the protocol was three hours, during which three series of hourly and simultaneous measurements of $\mathrm{VO}_{2}$ and of the REE were performed by the method of Fick and by indirect calorimetry. All patients were submitted to invasive hemodynamic monitoring and to indirect calorimetry by the bedside using a portable calorimeter. In parallel, venous blood specimens were collected from the proximal orifice (right atrium) and from the distal orifice (pulmonary artery) of the Swan-Ganz catheter and arterial blood was obtained from the radial artery for blood gas analysis. The samples were used for the determination of hemoglobin $(\mathrm{Hb})$ concentration, arterial blood oxygen saturation $\left(\mathrm{SaO}_{2}\right)$, venous blood oxygen saturation $\left(\mathrm{SvO}_{2}\right)$, and arterial and venous blood partial oxygen pressure $\left(\mathrm{PaO}_{2}\right.$ and $\left.\mathrm{PvO}_{2}\right)$ respectively. After obtaining $\mathrm{VO}_{2}\left(\mathrm{~mL} \cdot \mathrm{min}^{-1}\right)$ by the method of Fick and oxygen content in arterial and venous blood, it was possible to calculate REE (kcal.day ${ }^{-1}$ ) according to the equations described below:

\section{(1) $\quad \mathrm{REE}=\mathrm{VO}_{2} \times 4.838 \times 1.44$ $\mathrm{REE}=\mathrm{VO}_{2} \times 6.996$}

Where $4.838 \mathrm{kcal} . \mathrm{L}^{-1}\left(20.2 \mathrm{~kJ} . \mathrm{L}^{-1}\right)$ is the caloric value of oxygen of a respiratory quotient (RQ) of approximately 0.824 (the mean value obtained for the present population as measured by indirect calorimetry), assuming a nitrogen excretion of 13 to $15 \mathrm{~g}$. day ${ }^{-1}$, and 1.44 is the conversion factor for kcal.day ${ }^{-1}$. The method of Fick uses the following equations for $\mathrm{VO}_{2}$ and REE calculations: ${ }^{12,13}$

(2) $\mathrm{VO}_{2}=\mathrm{CO} \times\left(\mathrm{CaO}_{2}-\mathrm{CvO}_{2}\right) \times 10$

$$
\begin{aligned}
& \text { Where: } \\
& \mathrm{CO}=\text { Cardiac output }\left(\mathrm{L} \cdot \mathrm{min}^{-1}\right) \\
& \mathrm{CaO}_{2}=\text { Arterial } \mathrm{O}_{2} \text { content }\left(1.38 \times \mathrm{Hb}^{-} \mathrm{SaO}_{2}\right)+ \\
& \left(0.00301 \times \mathrm{PaO}_{2}\right) \\
& \mathrm{CvO}_{2}=\text { Venous } \mathrm{O}_{2} \text { content }\left(1.38 \times \mathrm{Hb} \mathrm{SvO}_{2}\right)+ \\
& \left(0.00301 \times \mathrm{PvO}_{2}\right)
\end{aligned}
$$
we obtain:

By replacing the above values in equation (2),

$$
\text { (3) } \begin{aligned}
& \mathrm{VO}_{2}= \mathrm{CO} \times\left[\left(\left(1.38 \times \mathrm{Hb}^{\prime}\left(\mathrm{SaO}_{2}-\mathrm{SvO}_{2}\right)\right)+\right.\right. \\
&\left.\left(\left(0.00301 \times\left(\mathrm{PaO}_{2}-\mathrm{PvO}_{2}\right)\right)\right] \times 10\right)
\end{aligned}
$$

By replacing the values of equation (3) in equation (1), we obtain the equation below:

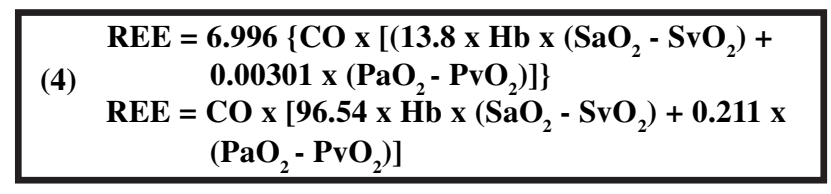

However, the addition of the value of $0.211 \times\left(\mathrm{PaO}_{2}\right.$ $\mathrm{PvO}_{2}$ ) from the above equation represents less than $1 \%$ of the final result of the calculation. On this basis, the final 
equation summarized for practical purposes is as follows:

\section{(5) $\mathrm{REE}=\mathrm{CO} \times\left[96.54 \times \mathrm{Hb} \times\left(\mathrm{SaO}_{2}-\mathrm{SvO}_{2}\right)\right]$}

Indirect calorimetry was performed in all patients using the DELTATRAC II Metabolic Monitor portable calorimeter (Datex-Ohmeda, Finland). Barometric and gas pressure was calibrated before each protocol. Each patient was submitted to three hourly series of consecutive $\mathrm{VO}_{2}$ measurements lasting 30 minutes each, for a total of 45 measurements. The two assessment methods were compared by the nonparametric sign Wilcoxon test for two correlated samples. The level of significance was set at $\mathrm{p}<0.05$ for all comparisons. The Pearson correlation coefficient was also used to determine the correlation between the REE values obtained by the three methods

\section{Results}

The study was conducted on 15 hemodynamically stable patients (11 males and four females) with a diagnosis of septic shock admitted to the intensive care unit between the third and fifth day of evolution. Mean age was $41.3 \pm$ 18.9 years. The mean prognostic APACHE II index was 22.6 \pm 7.2 , with a calculated death risk of $46.1 \pm 27.7 \%$. The mean sepsis score (SS) was $20.3 \pm 9.5$. The overall mortality rate for the population studied was $20 \%(n=3)$. The main clinical and demographic data of the patients are presented in Table 1. Most patients $(60 \% ; n=9)$ had pneumonia with acute respiratory insufficiency. No complication occurred due to the procedures performed during the study (venous catheterization, arterial puncture and indirect calorimetry). The mean REE obtained by indirect calorimetry (IC) was $1669 \pm 271 \mathrm{kcal}^{-d_{a y}{ }^{-1}}$ and the values calculated by the equations of BRANDI and LIGGETT were $1815 \pm 355$ and $1361 \pm 277$, respectively (Table 2 ). The differences in the values obtained by indirect calorimetry and in the predictive equations was $+8.7 \%$ (IC $x$ BRANDI) $(\mathrm{p}<0.5)$ and $-22.7 \%$ (IC x LIGGETT) $(\mathrm{p}>0.5)$. The correlation coefficient between indirect calorimetry and the BRANDI equation was 0.80 (Figure 1), and the correlation between indirect calorimetry and the LIGGETT equation was 0.58 (Figure 2).

TABLE 1 - Clinical diagnoses and demographic data of the population studied. Age = years, Weight $=\mathrm{kg}, \mathrm{Height}=$ $\mathrm{cm}, \mathrm{AP}$ II = APACHE prognostic index II, Death Risk = Death risk calculated by AP II (\%), SS = Sepsis Score (Sepsis grading).

\begin{tabular}{clcccccccc}
\hline Patient & Diagnosis & Age & Sex & Height & Weight & AP II & \% RO & SS & Death \\
\hline 1 & HI* +Pneumonia & 28 & M & 173 & 67 & 20 & 28 & 27 & No \\
2 & Pneumonia & 39 & F & 150 & 53 & 31 & 73 & 21 & Yes \\
3 & HI + Trauma of the sternum & 35 & M & 177 & 74 & 12 & 11 & 26 & No \\
4 & Pneumonia & 38 & F & 162 & 62 & 11 & 14 & 12 & No \\
5 & HI + Trauma of the sternum & 19 & M & 177 & 67 & 17 & 11 & 45 & No \\
6 & Amputation of an upper Limb & 16 & M & 174 & 65 & 26 & 55 & 9 & No \\
7 & Pneumonia & 78 & F & 163 & 70 & 28 & 66 & 10 & No \\
8 & Pneumonia & 32 & M & 167 & 63 & 28 & 72 & 11 & No \\
9 & HI + Trauma of the sternum & 31 & M & 176 & 70 & 15 & 16 & 17 & No \\
10 & Cellulitis of the lower limbs & 22 & M & 170 & 70 & 26 & 73 & 25 & No \\
11 & Chagasic megacolon & 69 & M & 160 & 60 & 33 & 88 & 26 & Yes \\
12 & Pneumonia & 48 & M & 177 & 80 & 24 & 52 & 15 & No \\
13 & Pneumonia & 68 & M & 160 & 58 & 27 & 63 & 16 & No \\
14 & PO Neurosurgery+Pneumonia & 55 & M & 170 & 80 & 27 & 58 & 17 & Yes \\
15 & Polytraumatism+Pneumonia & 41 & F & 162 & 88 & 14 & 11 & 28 & No \\
\hline Mean & & 41.3 & & 167.9 & 68.5 & 22.6 & 46.1 & 20.3 & 9.5 \\
SD & & 18.9 & & 8.1 & 9.2 & 7.2 & 27.7 & \\
\hline
\end{tabular}

* HI = Head Injury 


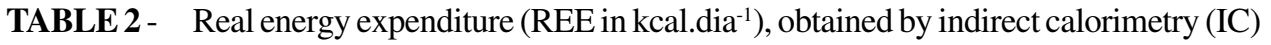
and by the Brandi $\left(\mathrm{REE}=\mathrm{VO}_{2} \times 6.996\right)$ and Liggett $\left(\mathrm{REE}=\mathrm{CO} \times\left[96.54 \times \mathrm{Hb} \times\left(\mathrm{SaO}_{2}\right.\right.\right.$ $\left.\left.-\mathrm{SvO}_{2}\right)\right]$ ) equations. The $\mathrm{VO}_{2}\left(\mathrm{~mL} \cdot \mathrm{min}^{-1}\right)$ and respiratory quotient $(\mathrm{RQ})$ values for each patient represent the mean of three serial hourly measurements.

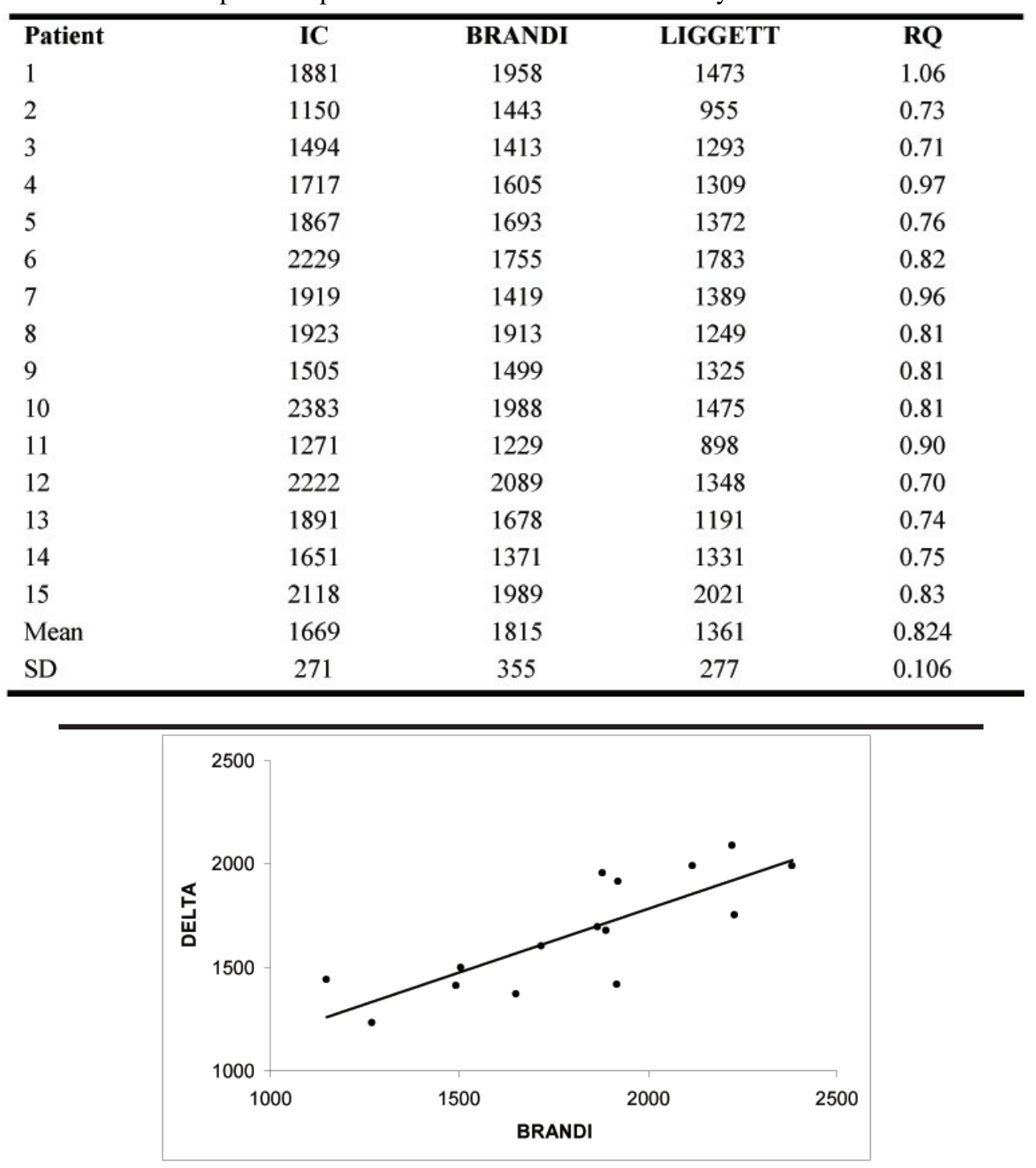

FIGURE 1 - Correlation between the mean values of serial real energy expenditure data obtained by indirect calorimetry (IC) and by the Brandi equation (BRANDI) $(\mathrm{n}=15 ; \mathrm{r}=0.80)$. Values are reported as kcal.day ${ }^{-1}$.

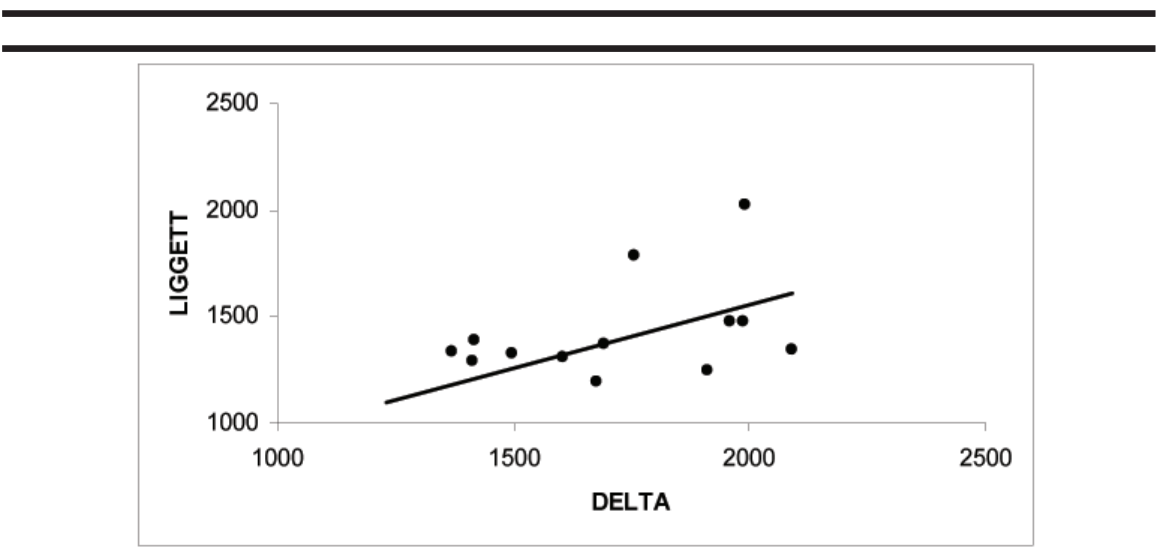

FIGURE 2 - Correlation between the mean values of serial real energy expenditure data obtained by indirect calorimetry (IC) and by the Liggett equation $($ LIGGETT $)(n=15 ; r=0.58)$. Values are reported as kcal.day ${ }^{-1}$. 
The objective of the present study was to compare the REE obtained by indirect calorimetry to the REE calculated by the predictive equations of Brandi and Liggett using hemodynamic $\mathrm{VO}_{2}$ data obtained by the method of Fick in patients with septic shock. Indeed, the REE of critically ill patients can be estimated by a wide variety of methods. Most of the formulas proposed in the literature are derivations of the equation of Harris \& Benedict, which was developed, in principle, for healthy individuals. Since, by definition, basal energy expenditure is the minimum energy requirement of healthy individuals at rest, a problem appears when this energy must be calculated for patients in special situations such as sepsis, trauma and extensive burns. Efforts performed by some authors to improve the precision of the equation of Harris \& Benedict for these situations by adding stress factors to the original equation have introduced an even greater source of error and perhaps of cost in the planning of nutritional therapy. Accurate administration of nutritional therapy is important for this patient population since it is well known that insufficient nutrient administration depresses the ventilatory drive ${ }^{17}$, reduces the strength of respiratory muscles ${ }^{18}$, and generates immunodepression $^{19}$. On the other hand, overnutrition causes hyperglycemia and fatty liver infiltration and may favor the onset of respiratory acidosis and delay of patient weaning from the respirator. ${ }^{20}$ On this basis, since over- or undernutrition is deleterious, indirect calorimetry became the gold standard for the assessment of energy requirements.

We attempted in the present study to asses two equations based on hemodynamic data and to correlate them with calorimetry, especially considering that in most intensive care units a three-lumen catheter is routinely introduced into the pulmonary artery for purposes of hemodynamic exploration. We opted for the assessment of the two most commonly used equations, i.e., the equations of Brandi and of Liggett. Originally, Liggett et al ${ }^{11}$, in 1987, suggested a new method for determining the REE using a catheter positioned in the pulmonary artery. These authors developed an equation based on hemodynamic data and correlated it with classical calorimetry. According to this initial study, there was a good correlation between the two methods $(r=0.90, p<0.0001)$.

On the other hand, Flancbaum et al. ${ }^{9}$, in 1999 , studied 36 critically ill and mechanically ventilated patients and detected a weak correlation between the REE measured by indirect calorimetry and by the Liggett equation $(\mathrm{r}=$ 0.28 ). The authors attributed these findings to the fact that any variation in one of the components of the Fick equation may introduce errors in the calculation of the REE. According to the cited authors, $\mathrm{SvO}_{2}$ may fluctuate during the study period because a fall in its value below $60 \%$ may indicate increased tissue oxygen consumption or the impairment of one of the variables related to oxygen transport. ${ }^{21}$ Although this information has a certain logic, the present patient series showed $\mathrm{SvO}_{2}$ and $\mathrm{SaO}_{2}$ within normal limits $\left(\mathrm{SvO}_{2}=80 \pm 5 \%\right.$; range $=65-88 \% ; \mathrm{SaO}_{2}=99 \pm$ $1 \% ;$ range $=96-100 \%)$, and the correlation detected $(\mathrm{r}=$ 0.58 ) is unlikely to be responsible for the small variations of these variables. Another potential explanation for the weak correlation between the two methods may be due to the relation between oxygen supply and demand, a situation described for sepsis. ${ }^{22}$ However, the most plausible reason, which was also the major challenge for the validation of this initial concept, is related to the mathematical coupling of the different hemodynamic variables involved in the calculation. ${ }^{23}$

The present patients showed an energy consumption of $1669 \pm 271 \mathrm{kcal}$ and an APACHE II score of $22.6 \pm 7.2$. These data are indicative of metabolic stress. Interestingly, the disease severity scores have been used to predict the REE of critically ill patients. Swinamer et al. ${ }^{24}$ demonstrated that patients with an APACHE II score $>20$ presented a very poor correlation between calorimetric data and data obtained by the method of Fick, with differences of up to $50 \%$ being detected between the two methods. Technical errors or misinterpretation of the results may also be introduced in both methods for the calculation of $\mathrm{VO}_{2}$. It should be pointed out that the calculation of $\mathrm{VO}_{2}$ by the method of Fick has an inherent limitation represented by the fact that this procedure does not take into account pulmonary $\mathrm{O}_{2}$ consumption. Total $\mathrm{O}_{2}$ consumption may be underestimated by as much as $25 \%$ in the presence of pulmonary infections in patients on mechanical ventilation.

With respect to the proposed calculation of the REE by the equation REE = VO $\times 6.996$ using the VO obtained by the method of Fick, Brandi et al. ${ }^{12}$ compared the calculation of energy expenditure by the method of Fick and by indirect calorimetry in a group of spontaneously ventilating 26 patients during the postoperative phase of interventions due to various types of trauma. These authors detected an excellent correlation between the two methods $(\mathrm{r}=0.96, \mathrm{p}<0.001)$. It should be pointed out that all the patients studied here were submitted to mechanical ventilation and, even so, the correlation between the two methods was 0.80 . We used the same equation because the 6.996 variable (equation 1) was obtained from a mean RQ of 0.827 , extremely close to the mean value of 0.824 detected in the present patient series (Table 2). In this respect, it should be emphasized that the introduction of a fixed RQ value $(0.824)$ in this equation and a nitrogen excretion of 13 to 15 g.day ${ }^{-1}$ introduces an error of approximately $3.6 \%$ because the caloric value of oxygen is 4.686 to 5.047 for an RQ with a physiological variation of 0.70 to 1.00 , respectively. For the calculation of energy expenditure this margin of error can be disregarded.

\section{Conclusion}

Although indirect calorimetry is the most reliable method for the determination of the energy needs of a given patient, the satisfactory correlation detected between calorimetry and the Brandi equation, and the small difference of only $8.7 \%$ between the two methods permit us to propose the use of the equation $\mathrm{REE}=\mathrm{VO}_{2} \times 6.996$, from the $\mathrm{VO}_{2}$ obtained in the method of Fick, even for septic patients under mechanical ventilation. The present study suggests that the prediction of energy expenditure by this simple procedure can be used for clinical purposes, especially in intensive care units where only the technique of insertion of a three-lumen catheter into the pulmonary artery is available. In addition, the equation uses only $\mathrm{VO}_{2}$ as the variable to be estimated, which is about $75 \%$ of the calculation of total energy expenditure. ${ }^{13}$

\section{References}

1. Kiney JM. Metabolic responses of the critically ill patient. Crit Care Clin. 1995;11:569-86.

2. Hill AG, Hill GL. Metabolic response to severe injury. Brit J Surg. 1998;85:884-90

3. Ultman JS, Bursztein S. Analysis of error in the determination of respiratory gas exchange at varying $\mathrm{FiO}_{2} \mathrm{~J}$ Appl Physiol. 1981;50:210-6.

4. Matarese L. Indirect calorimetry: Technical aspects. J Am Diet Assoc. 1997;97:S154-60.

5. Harris JA, Benedict FG. A biometric study of basal metabolism in man. Washington, CO, Carnegie Institute of Washington. 1919, Publ. $\mathrm{n}^{\circ} 279$.

6. Long CL, Schaffel N, Geiger JW, Schiller WR, Blakemore WS. Metabolic response to injury and illness: estimation of energy and protein needs from indirect calorimetry and nitrogen balance. JPEN. 1979;3:452-6. 
7. Daly JM, Heymsfield SB, Head CA, Harvey LP, Nixon DW, Katzeff H, Grossman GD. Human energy requirements: overestimation by widely used prediction equation. Am J Clin Nutr. $1985 ; 42: 1170-4$.

8. Van Lanschot JJ, Feenstra BWA, Vermeij Cg, Bruining HA. Calculations versus measurement of total energy expenditure. Crit Care Med. 1986; 14:981-5.

9. Flancbaum L, Choban PS, Sambucco S, Verducci J, Burge JC. Comparison of indirect calorimetry, the Fick method, and prediction equations in estimating the energy requirements of critically ill patients. Am J Clin Nutr. 1999;69:461-6.

10. Zauner C, Schuster B, Schneeweiss B: Similar metabolic responses to standardized total parenteral nutrition of septic and nonseptic critically ill patients. Am J Clin Nutr. 2001;74:26570.

11. Liggett SB, St Jonhn RE, Lefrak SS. Determination of resting energy expenditure utilizing the thermodilution pulmonary artery catheter. Chest. 1987;91:562-6.

12. Brandi LS, Grana M, Mazzanti T, Giunta F, Natali A, Ferrannini E. Energy expenditure and gas exchange measurements in postoperative patients: Thermodilution versus indirect calorimetry. Crit Care Med. 1992;20:1273-83.

13. Brandi LS, Bertolini R, Calafa M. Indirect calorimetry in critically ill patients: Clinical applications and practical advice. Nutrition. 1997; 13:349-58

14. Bone RC, Balk RA, Cerra FB, Dellinger RP, Fein AM, Knaus WA, Schein RM, Sibbald WJ. Definitions for sepsis and organ failure and guidelines for the use of innovative therapies in sepsis. The ACCP/SCCM Consensus Conference Committee. American College of Chest Physicians/ Society of Critical Care Medicine. Chest.
1992;101:1644-55.

15. Knaus WA, Draper EA, Wagner DP, Zimmerman JE. Apache II: a severity of disease classification system. Crit Care Med. 1985;13:818-29.

16. Elebute EA, Stoner HB. The grading of sepsis. Br J Surg. 1983;70:29-31.

17. Doekel RC, Zwillich CW, Scoggin GH, Kryger M, Weil JV. Clinical semi starvation: Depression of hypoxic ventilatory response. N Engl J Med. 1976;295:358-61.

18. Kelly SM, Rosa A, Field S, Coughlin M, Shizgal HM, Macklem PT. Inspiratory muscle strength and body composition in patients receiving total parenteral nutrition therapy. Am Rev Respir Disease. 1984;130:33-7.

19. Good RA, Lorenz E. Influence of energy levels and trace metals on health and life span. JPEN. 1990;14:230-6.

20. Laaban JP, Lemarie F, Baron JF, Trunet P, Harf A, Bonnet JL, Teisseire B. Influence of caloric intake on respiratory mode during mandatory minute volume ventilation. Chest. 1985;87:67-72.

21. Ermakov S, Hoyt JW. Pulmonary artery catheterization. Crit Care Clin. 1992;8:773-806.

22. Tuchschmidt J, Oblitas D, Fried JC. Oxygen consumption in sepsis and septic shock. Crit Care Med. 1991;19:664-71.

23. Archie JP. Mathematical coupling of data: a common source of error. Ann Surg. 1981; 193:296303.

24. Swinamer DL, Phang PT, Jones RL, Grace M, King EG. Twenty-four hour energy expenditure in critically ill patients. Crit Care Med. 1987;60:63743.

25. Hensel M, Kox WJ. Increased intrapulmonary oxygen consumption in mechanically ventilated patients with pneumonia. Am J Respir Crit Care Med. 1999;160:137-43.

\section{Acknowledgements}

FAPESP - Fundação de Amparo À Pesquisa do Estado de São Paulo and FAEPA - Fundação de Apoio ao Ensino, Pesquisa e Assistência do HCFMRP-USP

\section{Correspondence}

Paulo Roberto Barbosa Évora

Rua Rui Barbosa, 367, Ap. 15

14015-120 Ribeirão Preto, SP, Brazil

Phone/Fax: (+55) 16 3602-2497

Conflict of interest: none

prbevora@netsite.com.br

How to cite this article:

Basile-Filho A, Martins MA, Marson F, Evora PRB. An easy way to estimate energy expenditure from hemodynamic data in septic patients. Acta Cir Bras [serial on the Internet], 2008; 23 Suppl 1. Available from URL: http://www.scielo.br/acb.

\section{Comments:}

Accurate nutritional therapy is important for critically ill patients such as the subjects studied in the present series; and, to determine the individual nutritional needs the measurement of REE is mandatory. The gold standard and the most reliable method for REE calculation is the indirect calorimetry. However, such method has some limitations because it is time consuming and requires an equipment of high cost. As stressed by the authors, the estimate of REE by using easier methods based on predictive equations such as the classical equation of Harris \& Benedict. ${ }^{5}$ have shown imprecise results in a wide variety of clinical situations. Thus, the authors have compared REE obtained by indirect calorimetry (IC) to the REE calculated by predictive equations (Brandi and Liggett) using the oxygen consumption ( $\mathrm{VO}_{2}$ ) obtained by Fick's method in 15 septic patients. A good correlation was found between the IC method and Brandi equation. The results support the authors' proposal of using the equation $\mathrm{REE}=\mathrm{VO}_{2}$ × 6.996 to calculate the diary caloric requirement for septic patients under mechanical ventilation.

\section{Antonio Carlos Pereira Martins}

Full Professor and Head, Division of Urology, Department of Surgery and Anatomy, Ribeirão Preto Faculty of Ribeirão Preto, University of São Paulo, Brazil. 